\title{
SAITE STORE 2.0: EXPERIENCE REPORT ON THE DEVELOPMENT OF AN IMPROVED VERSION OF A DIGITAL LIBRARY APPLICATION
}

\author{
Ana Emilia Figueiredo de Oliveira ${ }^{1}$ Katherine Marjorie Mendonça de Assis ${ }^{2}$ \\ Camila Santos de Castro e Lima² Carla Galvão Spinillo ${ }^{3}$ Elza Bernardes \\ Monier $^{2}$ Maria de Fatima Oliveira Gatinho² and Marcelo Henrique Monier \\ Alves Junior ${ }^{4}$ \\ ${ }^{1}$ Department of Dentistry I, Federal University of Maranhão, São Luís, Brazil. \\ ${ }^{2}$ UNA-SUS/UFMA, Federal Universityof Maranhão, São Luís, Brazil. \\ ${ }^{3}$ Department of Design, Federal University of Paraná, Curitiba, Brazil. \\ ${ }^{4}$ Campus of Porto Franco, Federal Instituteof Maranhão, São Luís, Brazil.
}

\begin{abstract}
The use of mobile technologies in the educational process has been generating positive results. In this context, institutions that work with Distance Education $(D E)$ need to update and adapt their processes to these innovations. Considering this trend, UNA-SUS/UFMA has built, in partnership with the Saite Group, a virtual library that enables fast and free access to its contents using mobile devices. With the expansion of the tool's use, the institution invested in a new version to provide a better experience to its users. This paper aims to perform a detailing of the Saite Store new version, showing its operation and the technological implementations carried out. Finally, the importance of performing updates in the application is highlighted, considering its great potential for use by more than twenty thousand users.
\end{abstract}

\section{KEYWORDS}

Distance education, virtual library, e-learning, mobile.

\section{INTRODUCTION}

Currently, the ease of access to these devices has caused a growing number of people to have one or more devices and know how to handle them [1]. Therefore, mobile learning becomes a reality, allowing access to educational content and knowledge sharing with autonomy, regardless of economic, social and geographical factors, through mobile interaction platforms.

Distance Education (DE), already widespread in adult education, especially in higher education, has excelled in health continued education [2]. In Brazil this trend is confirmed and because of that the regulatory institutions such as the Ministry of Education, have become aware to the creation and imposition of rules to regularize the practices on Health Distance Education, in order to ensure quality in this mode, aligning to the presential initiatives. Regulation is essential to ensure that the economic appeal offered by DE do not encourage the multiplication of courses without enough theoretical and scientific basis to form good professionals [3]. 
The modality has expanded in various ways, following the major advances both with regard to the evolution of technologies, and in relation to the renewed conceptions in the area of education. In this sense, one of the branches of DE that has gained more and more space is the m-Learning (Mobile Learning). The term refers to the use of mobile devices (such as cell phones, smartphones, PDAs, handheld computers, tablet PCs, laptops, and personal media players) to mediate the learning process. The $\mathrm{m}$-Learning expands as mobile devices become indispensable in the routine of individuals. The need to update and sync with the virtual world experienced in the contemporary world makes people rarely distance themselves from their mobile devices. The $\mathrm{m}$-Learning initiatives are based on the observance of the ubiquitous character of these devices, taking advantage of the fact that their presence is so latent in the lives of individuals, using that to bring them closer to educational practice [4].

The possibility to facilitate the access of the student to course content through mobile applications known as m-Learning presents itself as an important and powerful tool for Distance Education. M-Learning is defined as the ability to learn anywhere at anytime without the need for a physical connection to network cables [5].

Recent studies suggest that medical science students have positive perceptions regarding mobile learning [6][7].In addition, students report that m-Learning tools have been as effective as traditional teaching in clinical environments and formal learning environments [8][9].

The Saite Store is one of the tools that enable the dissemination of knowledge with quality. This virtual library makes e-books available for free. Its content is mostly aimed at health professionals, since the training of workers in this area imposes the need for permanent qualification and innovation of educational practices, in a dynamic and systematized way [10]. The objective of this work is to describe the experience of developing a new version of the Saite Store, as well as describing the virtual library.

\section{MOBILELEARNING}

Mobile learning or m-learning, is the learning through the use of mobile devices as a platform for studies [11], through the integration of several processing and data communication technologies. With this, it allows students and teachers a greater possibility of interaction, providing education at a more comprehensive level. It enables learning to no longer be limited by location, time, and a physical connection line, with more expensive equipment such as a desktop computer or a laptop [12] [13].

M-learning is an even more flexible form of education, which creates new spaces and ways of interaction, not just an extension of formal education. Among the advantages of using $\mathrm{m}$ - learning as a teaching-learning strategy, it is worth to mention: acquiring knowledge anywhere, requiring only that the users have their device at hand, even in movement; being able to access the learning system you want, when and where you need it; expanding the learning resources, each student can choose the material and method he/she finds most convenient; enabling learning in real context, since it is possible to exchange experiences with other users at different levels [14].

From these considerations, it is possible to see the relevance of m-learning implementation in the model of distance education.

\section{SAITE STORE1.0}

The Open University of Brazilian National Health System of the Federal University of Maranhão (UNA-SUS/UFMA), attentive to the expansion of smart phones market and following an 
increasingly current tendency of mobile devices use in education, developed the Saite Store: an application that offers content mostly in health area, which can be downloaded through the Play Store and Apple Store. The platform was developed in partnership with the Saite Group - research group focused on health, innovation, technology and education. In this application, users can download free e-books and manage them according to their interest by creating their own virtual library.

A multidisciplinary team formed by professionals from the areas of Instructional Design (ID), Graphic Design (GD) and Information and Technology (IT) participated in the development of Saite Store. The application was built using HTML5, CSS3 and JavaScript technologies in view of the strong application of these technologies in the market and their compatibility with major browsers such as Chrome, Firefox, Safari and Internet Explorer.

UNA-SUS/UFMA develops applications for mobile devices addressing mostly health care subjects since 2013. One of the main purposes to develop these learning tools is to provide material elaborated by experts in health care, primary care and public health, for free, and to be accessed through any type of mobile devices online and offline. In this way, it became possible to reach even those who live or work in remote regions, where Internet access is limited.

Nevertheless, despite of being innovative learning objects, which have become popular in a short period, there were some limitations to be overcome. Before SAITE Store creation, it was noted that as each application had to be searched and downloaded individually and it became uncomfortable for users to have an application for each book in their mobiles. Another limitation was the search in Google and Apple stores, which could direct users to various applications, not necessarily those produced by UNA-SUS/UFMA.

SAITE Store has emerged as a solution to these problems. It collects all the applications developed by UNA-SUS/UFMA, making easier for users to find and download the e-books they are interested in.

SAITE Store is, therefore, an application that works as a virtual store, providing access to e-books (interactive classic books) categorized by subject areas. The books address health issues and also cover topics from other areas such as Portuguese.

The production of first grade, free of access, free and unrestricted, educational materials prepared for professionals applied in the topics addressed; secondly, a web of international teaching dynamics, transforming learning into a routine, through the insertion of educational elements in the day-to-day of music lessons, with the use of mobile devices.

Currently, Saite Store already has more than 200 e-books distributed in 12 thematic areas. It is used by more than 22,000 users, proving to be useful in the democratization of the knowledge offered by UNA-SUS/UFMA. In this platform, users have the possibility to access free, interactive and updated content at any time, as well as it allows students of the institution to continue their studies even through other platforms.

\section{SAITE STORE2.0}

\subsection{Features}

In its first release, Saite was already a virtual library that featured easy-to-use e-books - with engaging design and interactive graphical animations - that used the least scrollbars in the text. This allowed the user to access all content on a single screen. Through the methodology of exploratory and stress tests with the application, the inability to implement new functionalities and to update the application with new e-books was detected. It has led to the decision to develop a more potent version of the application that would allow compatibility with a wider range of devices. 
A traceability process of version 1.0 weaknesses was then performed, listing requirements for the new version to be developed.

In this updated version, the application gives the user a more flexible and completely offline browsing experience, increasingly providing the user with autonomy to access intended content whenever and wherever they want.

In the previous version of Saite, it was only possible to navigate through the store with internet connection. When there was no connection, the user had access only to downloaded books.

With this upgrade, navigating through the application has become easier and totally off-line. This means a lot more independence: the user can perform any activities that the application makes available even without internet access; the connection is needed only for downloading e- books.

A new database architecture has been implemented for the server environment and the user's mobile device. With the operation of this data structure, the use of the offline application was allowed, since a mirror of the service is provisioned at the client.

In addition to the change in navigability, the new Saite Store also has a greater capacity of books storage than the previous version, mainly because of the improvement in the application's speed.

The new version has optimization algorithm for data provision and only once a day a mirror of the data that the application needs is generated. Two algorithms are used on the server: one to create a file with all available information and another only for new information.

Another interesting change is that the new Saite Store brings a more flexible design than the previous one and now the student has a tool more compatible and adaptable to different devices. It was sought to understand how the user uses his device and then a version that is better suited to reading was built - be it horizontal for tablets or vertical for smart phones. Specific versions were also developed for smart phones, adapted to the guidelines of each of the operating systems (iOS, Android, and Windows). According to the Google publisher (Play Store), the application's acceptance in approved devices has reached $100 \%$. In this paper, we dealt with the details of the version for Android devices.

\subsection{SaiteStore 2.0Detailing}

When the users open the app, they come across the home screen, which contains a preview of the thematic areas in the app that are displayed in rotating banner format. Below are e-books divided by some thematic areas, with an initial highlight for the recent e-books category, which presents the novelties of the store. This way, the user keeps informed about new content options. 


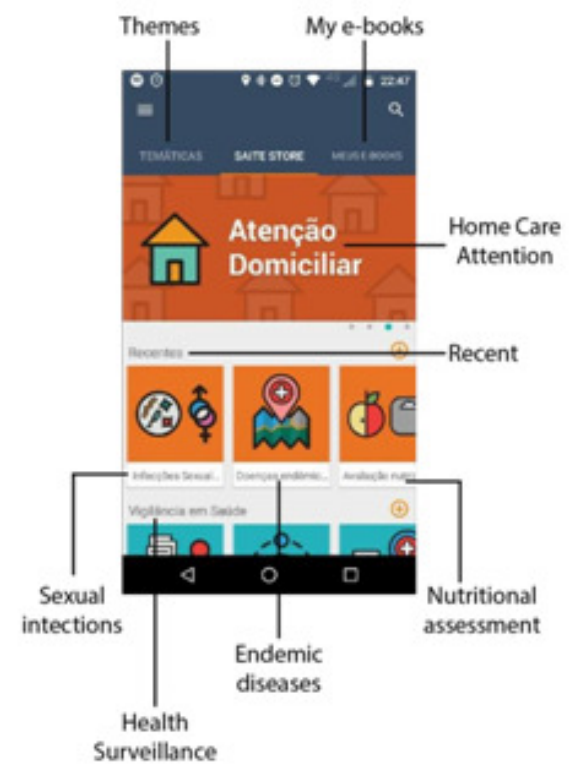

Figure 1: Saite Store Home screen.

The navigation through these lists occurs in the horizontal direction. So that the user can intuitively understand the navigation direction, the last e-book card in the line appears partially on the screen, encouraging him/her to scroll to get the rest of the information. Above these, the button with the plus symbol is included, to present the other e-books that compose the list.

The application's main functions are presented in the top menu for easy navigation. In this menu, the user will find: "Search bar", which works with data entry through typing or voice search, saving recent searches performed by the user; the "Themes" option that lists all the subject areas in which e-books are currently categorized in the store; and the "My e-books" option, which organizes all books that the user has already downloaded.

Together with the search button, there is a menu, indicated by an icon adapted to the language and layout on each device that presents a description of the application on the "About" button, a "tutorial", and the "exit" option.

The transition between these screens (main, thematic and my e-books) is evident: each one has a distinct appearance, to emphasize that they have different purposes, allowing a quick identification of the section where the user is.

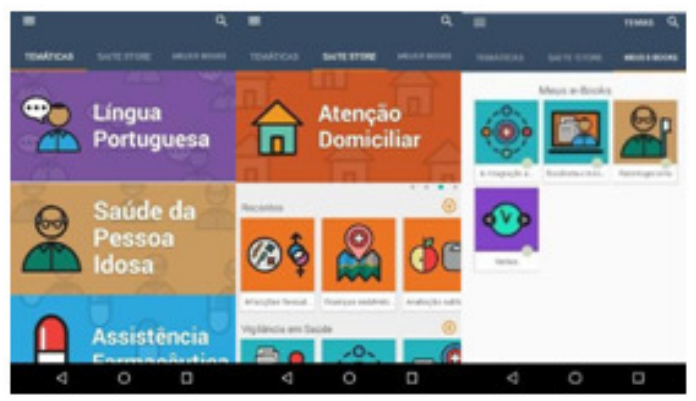

Figure 2: App's home screens. 
In the thematic areas screen, a list is presented containing the topics in which e-books are classified. Currently, the store presents 200 e-books divided into 12 thematic areas related to health, distance education, Portuguese language and scientific methodology. By clicking on the intended subject area, the user will find descriptive information about the content and all the ebooks that are part of the area.
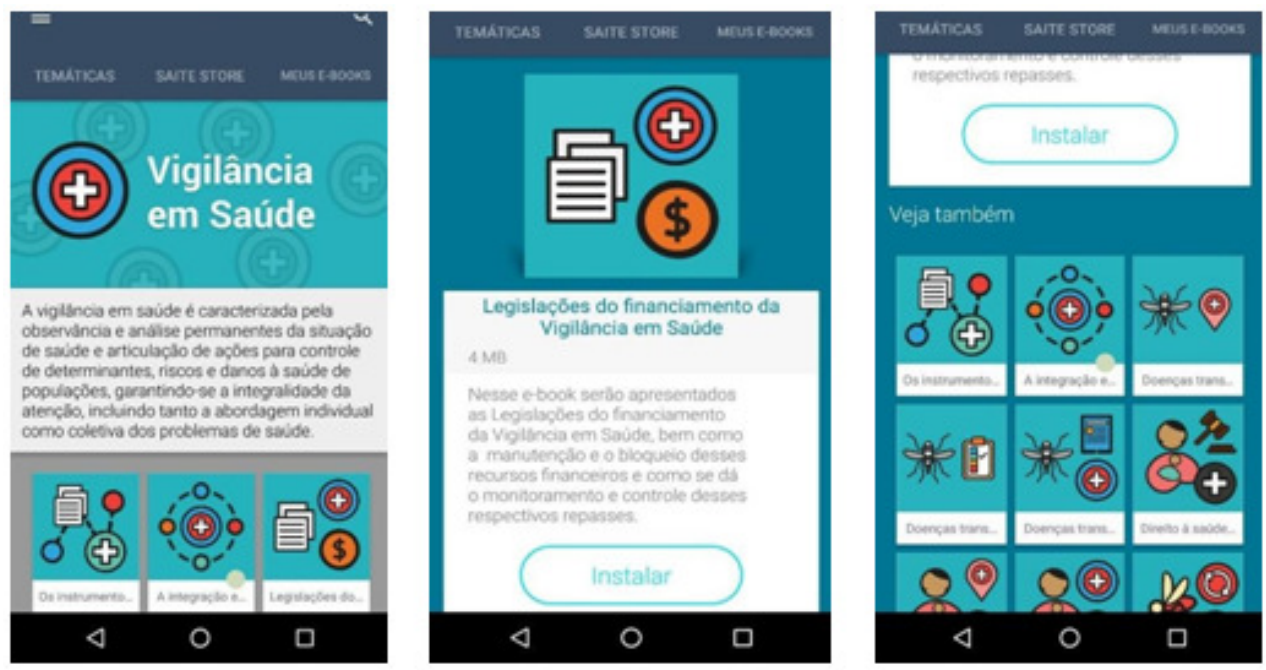

Figure 3: Screen with thematic area information, with e-book information and with related e-books.

When choosing an e-book, the user is redirected to the screen with information about its content, size, a button with installation action and a list of other e-books related to the chosen material.

By clicking on install, the user follows the installation of the material and is notified as soon as this process ends. With the e-book installed, the users can read or uninstall it. If they choose to read, they are directed to the e-book, where the content can be accessed. If they choose to uninstall the book, a warning screen pops up to confirm the action.

The e-books have a dynamic and interactive format and are updated constantly, according to the need for content renewal. Before starting to read the material, the user is informed when the last update occurred.

While reading the e-book, the application allows, by means of fixed buttons, the user to return to the homepage or return to the book description area.
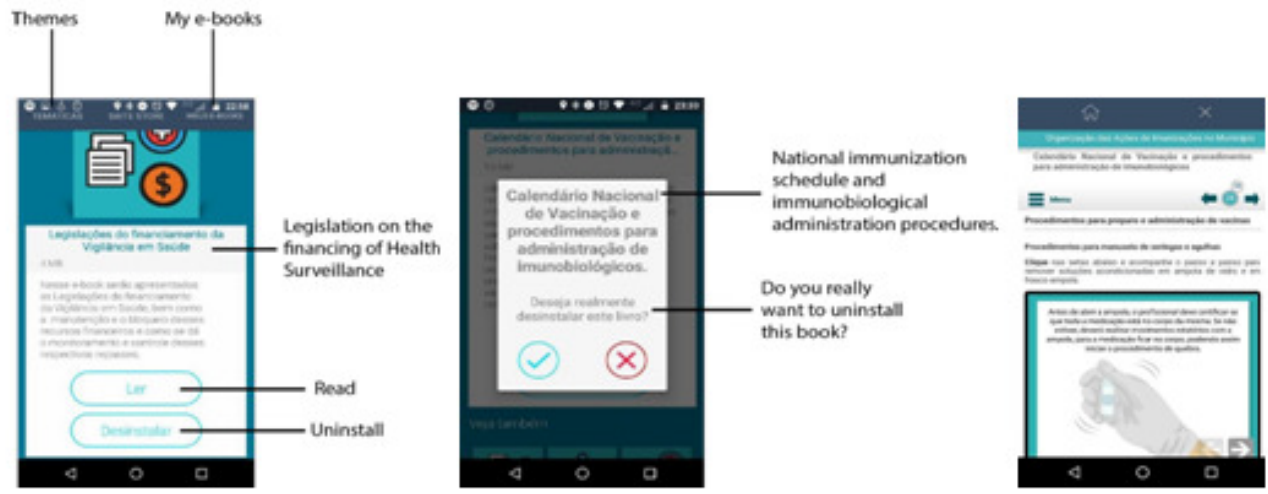

Figure 4: Read and uninstall functions, E-book uninstall alert and E-book and fixed buttons to return and. 
By clicking on install, the user follows the installation of the material and is notified as soon as this process ends. With the e-book installed, the users can read or uninstall it. If they choose to read, they are directed to the e-book, where the content can be accessed. If they choose to uninstall the book, a warning screen pops up to confirm the action.

All downloaded eBooks are flagged with a green indicator and listed in the "My eBooks" area, which allows the creation of a custom library. These books can be arranged alphabetically or by theme, according to user's viewing needs.

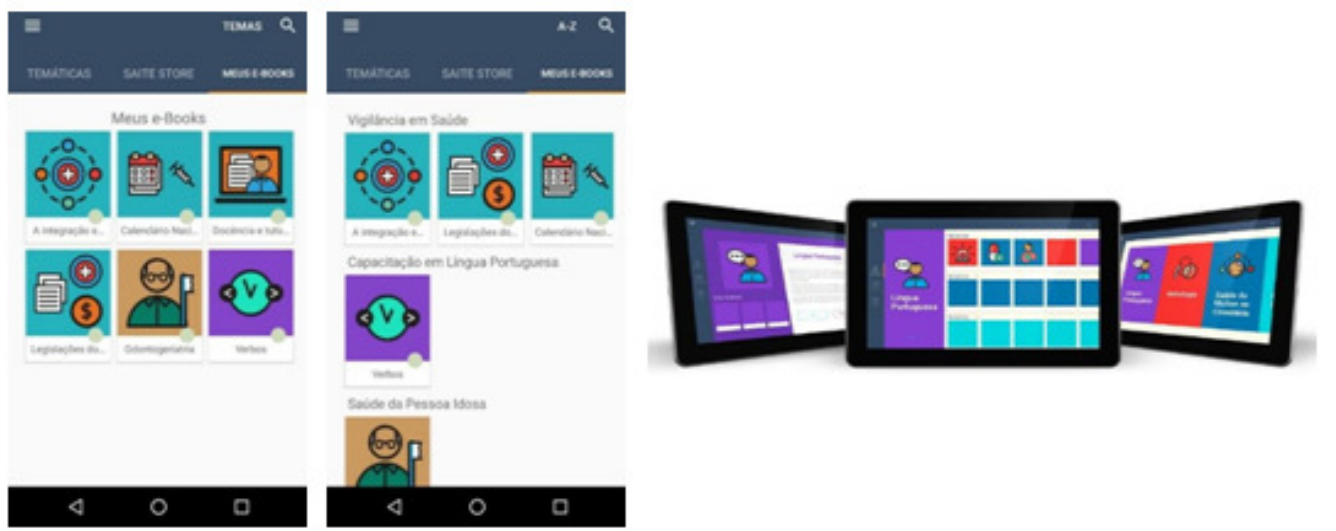

Figure 5: "My e-books" area arranged alphabetically, "My e-books" area organized by themes and Screens in tablet version.

For the tablet version, we worked on landscape orientation by re-adapting the elements to fit this guideline while retaining the application's functions and principles.

\section{CONCLUSIONS}

The use of applications that assist in students' studies routine has become a reality in education. In this context, Saite Store presents itself as a tool that allows access to quality free content, in an easy way. Currently, the store already has more than 21,860 downloads and presents great potential for new implementations.

For a version 3.0 of the store, some features have already been listed: the possibility of user sharing of information with other people; greater interaction with the users with dialog boxes that stimulate the permanence and facilitate even more their navigation in the platform; a module to collect data about the users' behavior in relation to the application (number of pages read, most downloaded and most uninstalled e-books, time of navigation in the application, etc.); internationalization of the store for English and Spanish versions; insertion of functionality that allows the users to reopen the book on the page where they stopped, if they close the application and open it again.

For version 2.0, it is planned to carry out surveys with users to collect information and feedback about their experiences and perceptions regarding the application and to validate the implementation of the new features listed for a new version.

SAITE Store figures as tool to promote continuing education in health, since it provides various e-books which address many topics in health field, and by no cost. The e-Books offered in the virtual store are powerful tools for health professionals learning, using any type of mobile device, with or without access to Internet, which results in more possibilities to improve knowledge, hence, resulting in better assistance to the population assisted. 


\section{REFERENCES}

[1] UNESCO. Diretrizes de políticas para a aprendizagem móvel. Brasil, 2014. Available at: <http://unesdoc.unesco.org/images/0022/002277/227770por.pdf>.

[2] Moran J. A EAD no Brasil: cenário atual e caminhos viáveis de mudança. Available at: $<$ http://files.educacao-e-tics.webnode.com/200000119-e8e55e9e03/Ead\%20-\%20Moran.pdf>.

[3] Mesquita KC; Silva JA, Igreja ACSM. Aplicabilidade da educação a distância na educação médica continuada. Brasília Med2012;49(2):111-117

[4] Park Y. A Pedagogical Framework for Mobile Learning: Categorizing Educational Applications of Mobile Technologies into Four Types. The International Review of Research in Open and Distance Learning, 12(2),78-102.

[5] Georgiev T, Georgieva E, Smrikarov A. M-Learning: A new stage of E-Learning. Proceedings of the 5th international conference on Computer systems and technologies.2004.

[6] Chase TJG, Julius A, Chandan JS, et al. Mobile learning in medicine: an evaluation of attitudes and behaviours of medical students. BMC Medical Education. 2018;18:152.

[7] Koohestani HR, SoltaniArabshahi SK, Fata L, Ahmadi F. The educational effects of mobile learning on students of medical sciences: A systematic review in experimental studies. Journal of Advances in Medical Education \& Professionalism. 2018;6(2):58-69.

[8] Schooley B, Walczak S, Hikmet N, Patel N. Impacts of mobile tablet computing on provider productivity, communications and the process of care. Int J Med Inf. 2016;88:62-70.

[9] Lee L-A, Chao Y-P, Huang C-G, Fang J-T, Wang S-L, Chuang C-K, et al. Cognitive style and mobile E-learning in emergent otorhinolaryngology-head and neck surgery disorders for millennial undergraduate medical students: randomized controlled trial. J Med Internet Res. 2018;20(2):e56.

[10] Campos FE, Lemos, AF, Vianna RF et al. Experiências exitosas da Rede UNA-SUS: trajetórias de fortalecimento e consolidação da Educação Permanente em Saúde no Brasil / Organização de Francisco Eduardo de Campos. [et al..]. - São Luís: EDUFMA,2017.

[11] Houser C, Thornton P, Kluge D. Mobile Learning: Cell Phones and PDAs for Education. In International Conference on Computers in Education. Japão,2002.

[12] Ribeiro OS, Medina DR. Mobile Learning Engine Moodle (MLE - Moodle): das funcionalidades a validação em curso a distância utilizando dispositivos móveis. Porto Alegre: UFRGS,2009.

[13] Shippee, M.; Keengwe, J. m-Learning: anytime, anywhere learning transcending theboundaries of the educational box. EducInfTechnol (2014) 19: 103. https://doi.org/10.1007/s10639-012- 9211-2.

[14] Kwon, S.; Lee, J. Design principles of m-learning for ESL. In Procedia Social and Behavioral Sciences 2, 2010. p.1884-1889. 


\section{AUTHORS}

Ana Emilia Figueiredo de Oliveira - Full Professor atthe Federal Universityof Maranhão. She holds an undergraduate degree in Dentistry from the Fluminense Federal University (UFF); a Specialization in Systems Management and Health Services (UFMA); a Masters and PhD degree in Dental Radiology from the State University of Campinas (UNICAMP) and a Post-Doctorate degree/Visiting Professor for the University of North Carolina/Chapel Hill-EUA (UNC-Chapel Hill/USA). Coordinator of the Open University of SUS/UFMA. Scientific Director of the Brazilian Telemedicine and Telehealth Association. Leader of the SAITE Research Group -

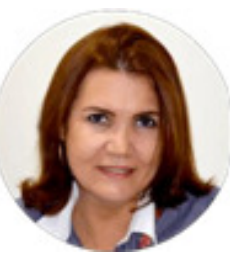
Technology and Innovation in Health Education (CNPq / UFMA). As a researcher, works mainly in the following subjects: Distance Education,Technology and Innovation in Health Education, Repercussions of oral alterations on women's health, Imaging, Primary Health Care, Mobile Applications, Management and Educational Monitoring Systems, Openinnovation.

Katherine Marjorie Mendonça de Assis- She holds a bachelor degree in Administration from the Federal University of Maranhão - UFMA; has experience in team management, communication, marketing and project management. Currently, she works at the Open University of SUS - UNA- SUS/UFMA as Coordinator of the Communication and Design Center. She previously worked at the institution as Secretary of Interinstitutional Relations and Production Supervisor.

Camila Santos de Castro e Lima - Graduated in Design from the Federal University of Maranhão (UFMA). Master's Degree in Design in the line of research Information and Communication, in the Graduate Program in Design of the Federal University of Maranhão (PPGDg / UFMA).

Carla GalvãoSpinillo- $\mathrm{PhD}$, University of Reading, GB, 2000 and postdoctoral fellow at the University of Avans, Netherlands, 2010) is a research professor at UFPR-Federal University of Paraná and collaborator of PPGDesign-UFMA and UNASUS / UFMA. She is a co-founder of the Brazilian Journal of Information Design - InfoDesign, and general editor of the IDJ-Information Design Journal (John Benjamins Publishers, The Netherlands). She is a member of the Health Design Network (Canada), the Saite Group (UNASUS / UFMA) and the National Science Education Network. Participated in the elaboration of regulation of Bolts of Magisterial Medicines of Paraná (Resolution SESA No 062/2013) and the Nutritional Labeling WG of ANVISA(2015).

Elza Bernardes Monier- Graduated in Dentistry from the Federal University of Maranhão (UFMA); Specialization in Distance Education (SENAC); Master in Health Sciences (UFMA) and PhD in Medical Sciences from the State University of Rio de Janeiro (UERJ). Currently, she works at the Open University of SUS - UNA-SUS / UFMA as Coordinator of Management of Educational Offers.
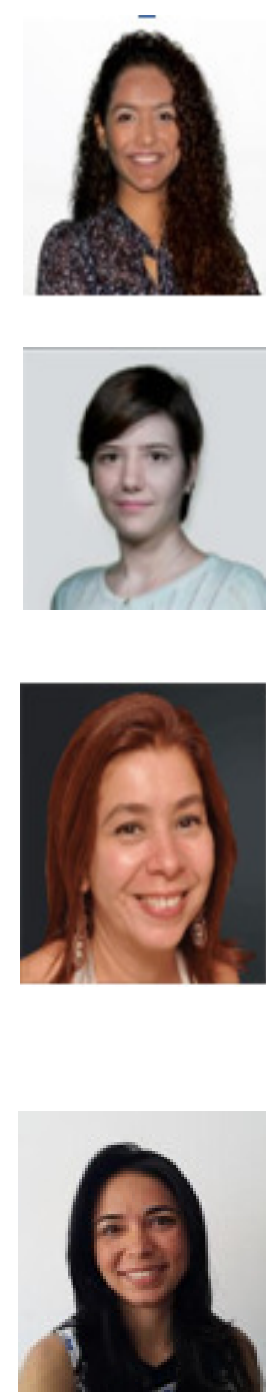
Maria de Fatima Oliveira Gatinho- Graduated in Economic Sciences from the Federal University of Maranhão (UFMA); Specialization in Health Systems and Services Management (UFMA) Currently working at the Open University of SUS UNA-SUS / UFMA as Coordinator of Financial Management.

Marcelo Henrique MonierAlves Junior - Graduated in Information System from the University Center of Maranhão (CEUMA); MBA in Project Management by FundaçãoGetúlio Vargas / FGV; Master in Computer Science, Federal University of Maranhão - UFMA. Currently, he works as a professor at the Federal Institute of Maranhão (IFMA).
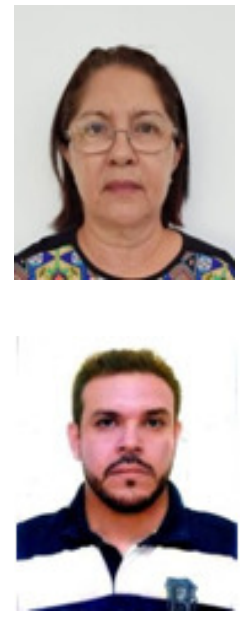